\title{
INFORMATION TECHNOLOGY DEVELOPMENT IN LITHUANIA: NEW TENDENCIES AND PERSPECTIVES
}

\author{
Narimantas Paliulis, Vida Elskytė, Juozas Merkevičius, Edmundas Trasauskas \\ Vilnius Gediminas Technical University, Sauletekio al.11, LT-2040VVilnius, Lithuania.E-mail: paliulis@vv.vtu.lt
}

Received: 10 January, 2003

\begin{abstract}
The goal of this study is to analyse processes which effect Lithuania's economical and political development, to present various expert opinions, describe tendencies and advantages of the information technologies (IT) integration in to Lithuania's daily life.

Recently started development of information society is the source of different contradictions and opinions, so these opinions are presented. To better understanding of present processes in Lithuania and forecast future trends we shortly introduced progress of IT in Lithuania. The factors which will stimulate development of IT in Lithuania are also described.

The IT integration processes in to separate business and social fields such as Education, Economics (Transport and communication, Electronic and electrical engineering, Chemical industry etc.), Government activity are analysed in this article. The suggestions on Lithuania's future development trends are proposed.
\end{abstract}

Keywords: information technologies, Lithuania's development, government activity

\section{Introduction}

Transnational companies [1], more powerful blocks, and large networks of communication systems play much more important role at present. Processes of integration are becoming more powerful in the economical and political sectors, and the national state is a basis for cultural identity which is important for the political and social structurization of mankind. Thanks to well-developed telecommunication systems, computerized information technology, transnational companies can develop standardized products, can on the basis of their tremendous budgets compete with the national states. Information technologies create conditions for a new cosmopolitically global culture which is free from any national restrictions. Such global culture have neither national roots nor character. Cultural eclecticism and ambivalence are characteristic to the globalism. On one side, it is a mixture of different traditional styles, their literature, music, and architecture, on another side - it is the unifying, unidirectional, uniform "scientific discourse" which is based on the infrastructures of technical commu- nications. Briefly speaking, cosmopolitan culture is created without any context of different components, is brought from everywhere and from nowhere, is borne from global telecommunication systems.

Global culture has three main features: it is universal, technical, and timeless. Neither of earlier existed cultures can claim for such universality independently to the extent of its diffusion areas. Such cultures emerged from specific human peculiarities during certain historical period. Global culture of nowadays cannot be rooted in time and place. It is timeless, widely disseminated in the environment, cut off from the past.

In spite of all these tendencies, the state is still remaining to be the main place where personal and collective identity is concentrated. The events of nowadays, "internationalization" of the global system also prove that the process of ethnification is not finished yet. Therefore, the state is still remaining to be the main geopolitical unit even if it is loosing its economical and political power. In cultural and psychological aspect it is essential and important for 
the political and social structurization of mankind. The national state, its culture is the basis of the cultural identity of Lithuania.

Different international organizations have gained great importance in the 20th century. They play central role in regulation of economical and security relations between sovereign states.

European Union is one of the most prominent institutions advocating the international integration. It is facing the obstacles created by national states, since in general both the states-candidates and the EU citizens consider the expansion rather cautiously. Politicians who make decisions and form the state opinion take much more favorable position with respect to the membership in the EU than the ordinary citizens of the states-candidates.

Recently started development of information society is the source of different contradictions and opinions [2]. Some people regard it as the start of really professionalized and solicitous society controlling its own citizens. Other people regard it as the birth of especially intellectual society able to process necessary information. There are people also who associate it with an inundation of banality, sensationalism, and misleading propaganda. Still other people point out to emergence of national state with increased role of information and its use; in accordance with the opinion of other people these changes can be qualified as radical transformation of a corporate organization where important role is played by the emergence of critical information.

Digital technologies can essentially change not only the management of the companies but of the state and society as well, including extension of the government services, administrative activity, character of democratic institutions, role of private sector, relationship between the citizens and state, future of national state, as well as the management of economics based on information technologies.

Definition and innovative apprehension of the Lithuanian national goals is influenced by the process of globalization and integration into global environments. Seeking to implement such national goals, the mechanisms of functioning of the state and society are modernized in order they would stimulate technological progress and innovations in all activity spheres.

One could assert after the review of the country's development tendencies that the conditions are being created allowing the growth of possibilities of human choice according to all aspects of the human life economical, social, cultural, and political aspect.
On one side, the human development means strengthening of the human powers by investments into his/ her education, development, and health protection increase of human capital; such process must involve all population of the country. On the other side, it also means creation of the conditions to an individual to use his/her powers seeking to participate in economical or creative activity, politics, public life, recreation, etc. The possibilities (not the results) for everybody shall become equal. The development of material and spiritual welfare in general can be defined by the distinction of several directions (some of them are analyzed in greater details in this paper):

- stable development of economics;

- healthy natural environment now and in the future;

- physical, legal, and social safety of an individual;

- development of human capital;

- development of civil society;

- culture and recreation.

All these problems are related to global public products, and it means that they will be solved on an international scale.

\section{Information technologies in Lithuania: favorable preconditions for the progress}

The situation in Lithuania is often described critically: we are lagging behind, we don't have anything, and we are outsiders. According to Lithuanian population poll data [3], 4.2 percent of Lithuanian population (or about 150,000 people) are browsing Internet each day on the average. With regards to these figures Lithuania is behind its neighbors and other European countries, not talking about the USA at all, but 9.4 percent of Lithuanian population is thinking about the installation of Internet in their households during the next year. Laptop or table-top PC is used at home by 12.9 percent of Lithuanian population over 15 years age, but another 12.3 percent of the population plan to acquire it in one year period. Thus, one can assert that information technologies are becoming more popular in Lithuania.

Let's pay attention to other factors also. One of the main indicators revealing the development of countries in the field of information and telecommunications is the percentage value of the ratio ITT/GDP. This ratio amounts to about 7 percent for Lithuania. According to this figure Lithuania stands on the 12th position world-wide [20] being ahead of such countries as Denmark, Germany, Belgium, etc. This market is expanding at a remarkable rate in Lithuania. The 
development of the situation can be described by the following figures: ITT market amounted to 233.3 MUSD in 1994, 392 MUSD in 1995, 479.3 MUSD in 1996, 618.5 MUSD in 1997, 807.8 MUSD in 1998, 863.6 MUSD in 1999, and to about 1,146.4 MUSD in 2000. Lithuanian experts in informatics are highly valuated in the foreign labor markets. The Law of Electronic Signature was adopted by the Seimas of Lithuania. Let us remember that similar law was passed in the USA just recently. According to the calculations of Infobalt, from 1995 the Government of the Republic of Lithuania spent 345 MUSD for information technologies (IT). Thus, on the other side, the issues of the development of information society attract attention in Lithuania [5].

One can assert that the preconditions of rapid technological progress exist in Lithuania the main of which would be following:

Lithuania already produces some high-tech products and supplies science intensive services.

High-tech biological products mostly for export are produced by the companies "Fermentas" and "Biotechna". Interferon and growth hormone for Western markets will be produced by an extremely modern factory of "Biotechna" which was erected recently. Efficient environment protection and rehabilitation technologies have been created by the company "Biocentras" which was founded ten years ago. Telecommunication equipment is being produced by the company "Elsis". The company "Geozondas" developed and sells mostly abroad the radar finder which, by the way, can be adjusted for the search of plastic mines. Accurate measurement equipment is produced by the company "Precizika" for the machine-tool industry. The company "Alna" performs software development orders to Western companies [7]. Software can serve as an example of high-tech services, along with the cardiological and other medical operations. There exist different sectors with very rapid development of Internet and information technologies, electronic business, accumulation of tremendous amounts of information, development of knowledge bases which will be used by high qualification experts in order to exchange expertise and knowledge via Internet. It is possible to assert therefore, that mutual relationship of these different sectors will grow and gain strength by means of information technologies. The companies of information technologies will develop new products used by the Lithuanian industrial enterprises, and it will mean specific relationship around one center information technologies.
Lithuanian industry is composed of sectors using a variety of fundamental technologies.

Mechanical, chemical, radioactive, electronic, and biological technologies are used by industry. Said technologies are developed widely, new Western equipment is acquired and own equipment is produced [7].

Concentration of industry and science is sufficient.

In some cities, especially in Vilnius and Kaunas, developed physical, technological, and business services infrastructure, as well as variety of economic sectors, creates good conditions for the start-up and development of the information technologies business individually or on the basis of cooperation.

Possibilities of the knowledge synthesis from different sectors are ensured by rather universal mutual cooperation between the graduates of the Lithuanian high schools.

Integration into the EU technological environment will make investments faster and cheaper.

Thanks to the integration Lithuanian scientists will obtain possibility to participate in joint researches or perform individual studies in a more efficient way by using the means and expertise of European researches [11]. It is also important, that integration promotes direct foreign investments which usually attract technological innovations as well. In spite of the fact that Lithuania didn't have many possibilities to implement and produce innovative ideas in parallel, the Lithuanian nation can be characterized by its special trend to engineering and innovations.

\section{Information technologies development strategy: the key elements}

Optimal development strategies exist for each country, the implementation of which predefines an optimal trajectory. The relation between the politics and trajectory is not a simple one, since first of all it depends upon egzogenic factors which cannot be controlled by the country. It is difficult also to determine endogenic factors in advance. Predominance of the software development sector in the national economy structure would be optimal in all aspects except of the circumstance that not each individual could be and would want to be a programmer. Technological level limits also exist in other sectors which are defined by difficulties to acquire certain abilities and knowledge [2]. Of course, such limits partially change together with the education level and concernment. 
The politics of development of information technologies must take into account available resources, existing situation, and short- and long-range goals.

\section{Factors stimulating the development of information technologies in Lithuania}

- it is planned to establish the Council of Science and Technologies which will include representatives of the state institutions and agencies, economical, scientific and other sectors and be presided by the Prime Minister, the task of which would be to consider and submit proposals to the Government on the main guidelines of information technologies policies and coordination of the information society development, with the implementation thereof in all country's development sectors [6];

- the strategies of all most important country's development sectors and their implementation programs are under preparation on the basis of which consolidated strategy of the country's development shall be prepared [10];

- development and use of information technologies is promoted, as well as the implementation of innovations based thereof in all industrial sectors of the country; additionally, an innovation fund has been created being the relevant structure which will help to transform technological progress and inventions into the products and services of information market able to compete in the international market;

- supported knowledge intensive development of industry and services as necessary basis of the country's economic progress is supported;

- the system of the state scientific-research institutions is more and more oriented towards the application researches [11];

- international cooperation is being developed in order to carry out the application researches first of all with the goal that the results of the global researches - new practically useful knowledge - could be used by all Lithuanian business enterprises;

- priorities are assigned to the development of scientific researches important for the country's economy. For example, sector of information technologies which will play an increasingly important role for the economic progress and social welfare of the state [13]. This sector is oriented to the intellectual work intensive production;
- scientific researches are supported which are carried out with the participation in international programs or specific projects and which will help to use results of globalization and integrate into the European scientific environment;

- scientific researches of international level offering possibility to use achievements of the world science;

- use of Lithuanian language is promoted with the development of information technologies, since this circumstance helps to develop and maintain national mentality. Modern technologies will present better possibilities to understand our own country, to strengthen social health of the society, to educate harmonious citizens of the country, etc. [11];

- special attention is being given to such sectors of science which will help to develop mutual interaction of high technologies on the basis of information technologies (lasers, biotechnologies, software, materials researches, mechatronics, etc.);

- continuous performance of investigating researches of high technologies necessary to the economic entities, including those sectors wherein high-tech production could be developed in Lithuania;

- elaboration of legislative framework in order to create better conditions for the investments into the development of information technologies, creation of business incubators and parks of science and technologies [21];

- creation of favorable environment for the investments of foreign high-tech companies in Lithuania [19];

- is planned to monitor the country's development, to analyze and evaluate its existing situation and trends, to stimulate processes of integration into the economic, social, and scientific environment of the European Union, to try to use technological resources of the European Union, to take over up-to-date institutional experience $[7 ; 20]$;

- development of the knowledge society in order to ensure integration of education, science, and economy, development of the principle of "studies throughout the whole life cycle", with the promotion of the society's participation [11];

- development of more elaborated mechanism of interrelations between the state authorities and society on the basis of civil initiative assisting in the development of the knowledge society [17]. 


\section{The overview of information technologies integration directions to $\mathbf{E U}$}

\section{Education}

One of the most important priorities shall be integration into the common market which is covering free movement of goods, services, capital, and labor.

Important role increasing the labor competitiveness is allotted to the preparation of experts in high schools [11]. As it can be seen from the statistical data on employment of the EU countries, starting from 1982 the employees with high education play decisive role in the development of different economic sectors [20]. Increasing the competitiveness of the experts with high education in the context of European integration, it is important to ensure feedback communication and information about the efficiency of the applied measures and their elaboration. It can be noted that the number of graduates in the fields of mathematical and information technologies, humanitarian sciences, fine and application arts, mass media means, religion and theology, business and administration, and other studies is increasing, and the number of graduates in the fields of agriculture, forestry, and fishery is decreasing [14]. Professional preparation meeting the demands of the labor market is one of the factors influencing the results of employment. It is understandable that the professional preparation is being developed in practical activity during the whole life cycle. However, adaptation in the working place and employment possibilities depend to great extent upon the professional preparation of the individual which is acquired in the teaching institution.

Scientific application work, adaptation and propagation of new work methods [2]:

- scientists working in different sectors are stimulated to use information technologies for the solution of specific scientific problems;

- conditions are created to the economic entities in order they could become familiar with the newest means and applied methods of information technologies;

- the experts are educated in order they could consult the manufacturers, services providers, and other organizations on the issues of implementation of information technologies;

- the system of priorities of adaptation of the newest methods of the scientific application researches related to the information technologies is under preparation.

\section{Economics}

The possibilities of the choice of an individual depend upon his/her income to the greatest extent. In a similar way the social, political, and cultural development of the country will depend upon the material and financial resources which are created by the country's economy. It is absolutely evident. Another aspect of the country's development, namely the dependence of the economic growth on the non-economic development is not so evident.

It is known already for a long time that the science is the resource of economic growth. However, it is also known that the knowledge by itself does not mean the economic progress: it can happen that knowledge is not used. Modern economic theories, recognizing importance of economic progress, stress the significance of individual abilities and incentives. These factors actually predetermine the development, implementation, and use of new technologies for the growth of economy. Nowadays it is much less expensive to create knowledge rather than to take it over. Lithuania is actively integrating into the global information (knowledge) society created by information technologies [1]. It is moving from the dominant agriculture to the dominant information services.

Due to the telecommunication progress it seems the world became smaller, and this means that everybody is becoming more dependants from the others, that cooperation became more intense, that competition became more fierce [4].

Attention is being given not only to the development of the IT sector, but also to other most successful industrial sectors (using IT innovations within these sectors) playing important role for the development of economics during the nearest years, such as [7]:

- production of chemistry and oil products;

- textile and clothing sewing;

- production of transport equipment (excluding automobile and truck sector);

- production of construction materials;

- printing and publishing industry, copying of publications;

- production of electrical equipment and devices;

- production of finished metal articles;

- industry of radio, television, and communication equipment and devices;

- timber industry and production of wooden articles and furniture.

Structure of economy is predetermined by the efforts and possibilities to produce products with higher 
added value and to provide such services. In the long run the growth of the high-tech products share in the country's economy is becoming dominant. The development of these sectors is also going on with the attention to quality. Development and production of the products having higher technical level, innovations of management and technologies guarantee higher added value and the growth of the efficiency of these sectors.

\section{Transport and communication}

Significant benefits can be expected from the existing geographical and geopolitical advantages. It's necessary to draw attention to the fact that it is not only important that Lithuania is crossed by two European transport corridors, but also to the circumstance that when the Eastern border of Lithuania will become the border of the EU the requirements will emerge with respect to the border protection quality which will be to certain extent related to the preparation of qualified staff to become members of the knowledge society and IT users.

Until the year 2010 it is planned to implement in Lithuania the projects of development of the transport infrastructure prepared in accordance with the Transport Infrastructure Requirements Evaluation Program initiated by the European Commission [18]. Taking into account the goal of proper implementation of the European transport needs necessary works will be carried out in order to develop motor roads, ports and terminals, to implement modern information technologies adjusted with the technologies used by the neighboring countries.

\section{Electronic and electrical engineering}

Until the year 2000 the remaining electronic industry consisted essentially of the production of television components and some other specialized products, for example, telecommunication equipment. Former great factories with their own research and design divisions have gone bankrupt or in best case were subdivided into a number of small companies providing technical services and sometimes authorized by known foreign companies. Several small enterprises producing hightech products were created on the basis of efforts of the experts of academic scientific institutes and their studies [7].

With the improvement of quality of the electric engineering products in order they could compete in the global markets and taking into account long-term perspectives of the sector's development great attention is given to the improvement of the technological level of production, especially collaborating with the mechanical and biotechnological production and scientific researches.

\section{Chemical industry and information technologies}

Lithuania is trying to consolidate its positions as the manufacturer and developer of medicaments and ferments genetic engineering. Strong scientific potential exist in this sector [9].

\section{Business services}

Business services play very important role being the factor joining different industrial sectors. The labor distribution principle preconditions that the general character business functions can be performed better by the specialized services companies achieving high professional level. In accordance with the evaluation of OECD, the following business services are most important in order to reach sufficient competitiveness level [21]:

- management consultancies;

- information technologies and telecommunications;

- technical;

- marketing and advertising;

- law and audit.

The information technologies services market is developing especially fast. It is necessary to stress that the business services are included to the business sector creating high added value, and therefore they are undoubtedly promising.

Continuous improvement of the growth factors and their use when developing technologies, management, abilities, and implementing efficient innovations shall create economic advantages of the country with respect to neighboring Eastern European countries.

\section{Government activity and information technologies}

Impact of governments to the development of information technologies plays very important role, but it is impossible to specify simple rules which should be followed by the governments. Of course, some of the rules are widely acknowledged, but many of other rules depend upon the specific internal and external conditions and variety of other factors. 
The implementation of the politics is non the less important than the politics itself. The politics based on the consensus, multipartial participation and transparency shall have more possibilities for the success. The authorities implementing this policy play an exceptional role to the development carrying out collaboration of all civil society sections [10].

The policy of development of the information technologies will be based on the following principles [6]:

- harmonious development includes many goals;

- policy of development of certain sectors depends on the policy of development of other sectors;

- the influence of governments upon the development is vitally important, but it is impossible to specify simple rules which should be followed by the governments;

- the implementation of the policies is as much important as the policy itself.

\section{Lithuania is a fairly developed country in the field of information technologies}

The following features shall be attributed to the Lithuanian innovations politics [2]:

National innovation programs shall have similar promotion and support measures as in the other countries of the EU.

Promotion of innovations on the state level shall be sponsored by specific state institutions - councils of science and technologies development, committees, representatives of the companies developing modern technologies.

Innovation programs and projects will be financed in accordance with the tender results;

Both the state and private funds will be invited for financing.

With the implementation of innovation programs important role will be played by the organizations providing consultancies on different aspects of the innovation assistance (innovation centers, technological centers, specialized consultancy companies, private educational companies, etc.).

$>$ In the process of the innovations development Lithuania will collaborate with other countries worldwide, will carry out joint projects, and will provide both intermediate and final results.

The innovations of information technologies and decision of the society to renew and assume obli- gations with respect to its own future will be promoted in Lithuania. These measures will ensure efficiency and competitiveness in the world market. The environment of the development of information technologies favorable to the investments and competitive on international scale will be created in this way in Lithuania.

The growth of innovations shall be ensured also by the efficient cooperation of universities, scientific research institutions, and business institutions. Such cooperation will also ensure development of business and creation of new working places, since the students still studying in the universities will be integrated into the labor market;

Favorable environment for the foreign high-tech companies' investments in Lithuania will be created, since an educated and mobile staff represents one of the attraction factors.

Multilateral services risk innovation services network of technological, legal, and financial services will be created.

Financing policy of the Lithuanian universities and scientific research institutes developing new technologies will be changed essentially. The institutes will function as the business enterprises earning their income necessary for the further researches.

\section{Conclusions:}

The country's development is broadening possibilities of choice of an individual with respect of all aspects of his/her life preconditioning the quality of life which is specified by the complex equilibrium of economical, social, political, and cultural factors, and in general in order the possibilities would be provided for in order to carry out the evaluations of the optimal management after special scientific studies will be carried out.

Lithuania has the preconditions of the rapid progress of information technologies including the following:

- Lithuania is already producing some of the hightech products and services;

- Lithuania has the potential of application researches;

- Lithuanian industry consists of the sectors using major parts of the fundamental technologies;

- There is a sufficient concentration of industry and science;

- There is a possibility to synthesize knowledge from different sectors of science; 
- Integration into the EU technological environment will make investments faster and cheaper.

The main issue must be focussed on education and development even for the medium-range period which will involve additional efforts and risks inseparable of the consultancy services delivery and assistance for the search of markets. The state arrangements will prevail in the long-term information technologies development strategy which will influence in a direct or indirect way the actions of individuals or organizations according to preferred direction.

Taking into account liberality of the present international trade, the country can develop itself in an economically profitable way only using its comparative (competitable) advantages on the basis of which it is possible to enter the world market and achieve benefits from the production scope and innovations. Theory and practice shows that modern economy doesn't have constant unsurpassable advantages; on the contrary, change of advantages is happening on a permanent basis. The country or company can develop its advantages by profitable production of some products or services, but it can loose such advantage at any time. Therefore, the advantage is not the crude oil or geographical location, but continuous improvement of growth factors and their use achieved by the development of technologies, management, abilities, and by the implementation of efficient innovations.

Since Lithuania doesn't have vast natural resources, the only solution will be the development of new information technologies and proceed along the innovations way.

\section{References}

1. V. Undzėnas and others. Problems and perspectives of international integration and national development: Lithuania, European Union, and the world, VU, Vilnius, 2000.

2. V. Undzènas and others. Conception of information society, its structure and the main features, VU, Vilnius, 2000.
3. Marius Povilas Šulauskas. Digital Lithuania 2001, ALF, Vilnius, 2001.

4. Virginijus Savukynas. What it is an information society, Artium Unitio, Vilnius, 2001.

5. Infobalt laikas' 2001. Catalogue, 2001.

6. Internet site of the association INFOBALT http:// www.infobalt.lt

7. Internet site of the Ministry of Economics of the Lithuanian Republic http://www.ekm.lt

8. Internet site of the Ministry of Environment of the Lithuanian Republic http://www.gamta.lt

9. Internet site of the Ministry of Health of the Lithuanian Republic http://www.sam.lt

10. Internet site of the Seimas of the Lithuanian Republic http://www.lrs.lt

11. Internet site of the Ministry of Education and Science of the Lithuanian Republic http://www.smm.lt

12. Internet site of the Ministry of Culture of the Lithuanian Republic_http://www.muza.It

13. Internet site of the Ministry of Social Affairs and Labor of the Lithuanian Republic http://www.socmin.lt

14. Internet site of the Ministry of Agriculture of the Lithuanian Republic http://www.zum.lt

15. Internet site of the Ministry of Finance of the Lithuanian Republic http://www.finmin.lt

16. Internet site of the Ministry of Country Protection of the Lithuanian Republic http://www.kam.lt

17. Internet site of the Ministry of Justice of the Lithuanian Republic http://www.min.tm.lt

18. Internet site of the Ministry of Transport of the Lithuanian Republic http://www.transp.lt

19. Internet site of the Ministry of Foreign Affairs of the Lithuanian Republic http://www.urm.lt

20. Internet site of the Ministry of Statistical Department of the Lithuanian Republic http://www.std.lt

21. Internet site of the Education Information Technologies Center http://www.ipc.lt 